http://dx.doi.org/10.12795/PH.1989.v04.i02.05

\title{
LA CRÍTICA TEATRAL EN EL SIGLO XIX. CRÓNICA DE UN ÉXITO DRAMÁTICO: EL ESCLAVO DE SU CULPA, DE JUAN ANTONIO CAVESTANY
}

\author{
Manuel Angel Vázquez Medel \\ Universidad de Sevilla
}

Exito literario y calidad literaria no son realidades correlativas. Y, las más de las veces, se nos presentan como incompatibles en vida del autor. Las Historias de la Literatura están llenas de autores discutidos o ignorados en su época, para los que la posteridad ha reservado un lugar de excepción. También nos abruman con el pesado silencio que gravita sobre innumerables autores que, según vamos descubriendo, alcanzaron en su época prestigio y popularidad. En ocasiones, los silencios de la posterioridad, correlativos a un éxito en vida tampoco, andando el tiempo, se revelan como justos. Bastaría citar el caso de Góngora como exponente del último supuesto. Y en cualquier caso, desde la reflexión que es propia a quienes se interesan por el hecho literario como producto y como proceso, cabe la pregunta: ¿cuál es la clave, en el fondo, de éxito y fracaso literarios? Tal vez el lema herreriano «agit in lucem veritatem tempus» sea cierto en términos absolutos. Pero, ¿cómo se produce esta acción iluminante de la «verdad» por parte del tiempo? ¿Es el tiempo sujeto real —o posible— de esta epifanía de la verdad en la luz? Es decir: ¿son éxito y fracaso medidas de la propia historicidad del hombre y sus obras? Y sobre todo: ¿hasta qué punto el intento de creación de una literatura «de masas» no va acompañado de una degradación objetiva de la estructura del texto?

Apelemos a la vía de la experiencia, contrastada históricamente. Examinemos un caso curioso y revelador. Nos referimos al comienzo de la aventura literaria de Juan Antonio Cavestany (Sevilla, 1861-1924), poeta, político, dramaturgo y comediógrafo, académico de la Española de la Lengua, militante del Partido Conservador y diputado en seis legislaturas (posteriormente Senador Vitalicio), 
acreedor del elogioso discurso académico de Maura con ocasión de su fallecimiento (Boletín de la Real Academia Española, 1924).

Cavestany constituye uno de los casos más llamativos de éxito precoz, y de prestigio mantenido en vida, de nuestra literatura. También de marginación injusta- y de olvido. Cuando hoy leemos el juicio que mereció a sus contemporáneos —claro está: a cierto colectivo de entre ellos, muy marcado ideológica y estéticamente - su producción teatral y su creación poética, apenas podemos dar crédito al desfase que media entre el contexto de producción y los distintos momentos de recepción literaria. El problema tal vez se plantee, no en la aplicación del concepto de calidad literaria, sino en el concepto en sí. ¿Qué permanece y qué cambia en el oteo distinto de distintos horizontes de expectativas?

La noche del jueves 13 de diciembre de 1877 se estrenaba en el Teatro Español de Madrid (antiguo Corral de la Pacheca) El esclavo de su culpa, comedia en tres actos y en verso de Juan Antonio Cavestany que, a la sazón, contaba con dieciséis años. Exito clamoroso que haría de esta obra inserción obligada del espectáculo teatral en provincias durante años (y aun en Ultramar), y que entre otros ilustres y distinguidos actores y actrices en su reparto, llegará a encontrar a la legendaria María Ǵuerrero.

Del mismo modo que los sismógrafos calculan la intensidad y el epicentro de un movimiento sísmico a partir de la propagación de su onda, la sociología de la literatura (y la denominación con más altos vuelos y distinta racionalidad «estética de la recepción») no disponen de más instrumento de evaluación de la medida receptiva en un determinado momento, que los testimonios de los lectores ( o espectadores) de los productos artísticos. Y a juzgar por tal criterio, El esclavo de su culpa provocó una profunda conmoción en los ambientes de la crítica teatral del momento. Asomémonos a las columnas de la prensa del día siguiente al estreno. Hemos consultado las notas de crítica teatral de casi toda la prensa madrileña del momento: El Globo, El Imparcial, La Mañana, La Patria, La Correspondencia, El Tiempo, La Política, Los Debates, Lealtad Española, El Conservador, Iberia, El Constitucional, El Cronista, La Gaceta, La Fe, El Popular, La Epoca y otras revistas como La Ilustración Española y La Academia o El Correo Militar. También hemos consultado algún diario de provincias, especialmente Sevilla, que citaremos oportunamente.

A la vez que establecemos los criterios de recepción, podremos comprobar la estructura básica de una nota de crítica teatral en el último tercio del XIX y, por tanto, delimitamos no sólo el objeto de evaluación, sino el patrón de medida (el canon crítico) y los instrumentos de medición (las proyecciones metodológicas), así como los resultados (el propio juicio crítico en cuanto sentencia más que en cuanto criterio). Creemos que es el único posible modo de proceder, desde la vertiente de la Teoría de la Literatura.

La crítica de $E l$ Globo es paradigmática al respecto. En primer lugar, una introducción presagiadora del juicio global: «Arrojemos lejos, muy lejos por hoy, 
pero teniendo cuidado de ver donde cae para recogerla luego, la pluma con que acostumbramos a escribir censuras, y saquemos la que, oxidada por falta de uso, tenemos guardada para los aplausos». Como telón de fondo (¡curioso compañero de la actividad teatral!) el fantasma de la crisis y la degradación; el maniqueísmo perfectamente plasmado en las expresiones metonímicas acerca de la pluma de las censuras y la pluma de los aplausos. Expresiones inequívocas que permiten establecer elementos de intertextualidad (o más sencillamente, de réplica) en los juicios críticos. En efecto, una de las pocas crónicas que restañan el entusiasmo con que es acogida la obra, publicada en Lealtad Española, arranca con las siguientes palabras: «Sin necesidad de que saquemos la oxidada pluma de los elogios, con la cual alguien trata de El esclavo de su culpa, obra estrenada anoche en el Español, diremos nuestra opinión acerca de ella, con la imparcialidad que siempre lo hacemos». Tópica invocación a la «imparcialidad» como garante del juicio crítico (valga la redundancia), presente en los criterios de casi todas las épocas.

Pero volvamos a la estructura básica de la crónica de El Globo, sintomática, como indicábamos, de la crítica teatral de prensa en el último tercio del XIX, a pesar de no ser ni la más extensa ni la más inteligente. Tras el comienzo preanunciador de encomiásticos elogios, así como presagiador del perenne asunto de la crisis del teatro (más que justificado en este contexto histórico), el juicio positivo proyectado sobre idénticas coordenadas: «La obra estrenada anoche en el teatro Español, bajo el título de El esclavo de su culpa, merece no eso, que es bien poco para su mérito, sino que saludemos a su autor D. Juan Antonio Cavestany, como a un poeta dramático de los que tanta falta hacen para regenerar la escena patria». La pretendida «regeneración de la escena patria» responde, claro está, a unas determinadas poética y retórica teatrales, que analizaremos más adelante, pero que como proyección de valores histórico-literarios buscarán el emparentamiento del joven autor con las consideradas como glorias del teatro hispano, sea como hecho, sea como aspiración. Así, la crónica de La Iberia indicaba: «Desde que se presentó El Trovador, escrito a los veinte años por el señor García Gutiérrez, y Juana de Arco, compuesta a la misma edad por el señor Tamayo, bien que sobre el pensamiento de una tragedia de Schiller, no registran los anales de la escena contemporánea un debut tan brillante como el del joven autor de $E l$ esclavo de su culpa». Y el crítico teatral de La Fe exclamaba: «iTiempo era de que en el teatro Español se representara una obra de verdadero mérito, como es la de que nos ocupamos!». La Política destacaba, igualmente, la madurez de la obra: «El esclavo de su culpa podría enorgullecer al autor de más reputación y de más envidiables condiciones: quien así empieza dará días de gloria a nuestra escena y téngase en cuenta que para ello no ha menester superar la primera prueba de su ingenio». «Per negationem», la crónica discordante de Lealtad Española, ya citada, indicaba: «No es ni sucesor de Calderón, ni de Tirso, ni de Lope de Vega, ni de Moreto, ni de García Gutiérrez, ni de Ayala y otros y otros mil autores antiguos y modernos el autor de El esclavo de su culpa; es, sí, el heredero de las aberraciones de algún hoy célebre escritor». A pesar de lo cual, el cronista reconocía que «la obra, en general, merece aplauso, máxime si se atiende a la corta edad del autor». 
Extremo obligado de la crónica teatral, El Globo nos ofrece el resumen del argumento, correctamente, esbozado, que con mayor contención o prodigalidad aparece en otras crónicas del día: «El asunto de la obra es el siguiente: un hombre seduce a una joven de quince años y la abandona, arrebatándole a la vez el fruto de su falta, y haciéndole creer que ha muerto. La joven seducida encuentra después otro hombre que se casa con ella, a pesar de todo, y que la ama y la considera cual merece por su noble y delicado proceder. Al dar principio la acción, dieciséis años después, llega a Madrid el seductor con ánimo de despedirse de su hija, que está al cuidado de una persona de su confianza y también de encomendarla a un amigo de la infancia: este amigo no es otro que el esposo de la mujer por él abandonada. Antes de hablarle encuentra a otro amigo de amigos que le pide consejos para seducir a una joven; él lo hace de buen grado, porque tiene ideas poco favorables de las mujeres en general, y resulta que conspira contra la honra de su misma hija. Esto, unido a que el esposo sabe por confesión propia que él ha sido el seductor de su mujer, y a que ésta se entera de que vive su hija, da lugar a situaciones de primer orden, y a escenas de ternura y sentimiento que arrancaron justos y nutridos aplausos, y obligaron al actor a presentarse en escena al final del primer acto, en medio del segundo y al finalizar éste y el tercero. No recordamos cuántas veces, pero sí que fueron muchas». Estas muchas veces, según nos recuerdan varios críticos teatrales, fueron dieciséis, tantas como sus años, según alguno (cf. El Tiempo) indicó: tres al final del primer acto, dos enmedio del segundo, cinco al final del mismo y seis al final de la obra.

La crónica teatral también debía recoger la reacción de los asistentes ante la representación, como termómetro difícilmente corregible por los críticos; y así lo hace El Globo: «Sería una puerilidad y hasta un insulto al público que tan espontánea y calurosamente aplaudió, rebuscar y señalar los pequeños defectos de una obra que tantas y tan grandes bellezas contiene, aparte de que sería más trabajoso que señalar bellezas en otras toleradas y elogiadas». Esos «pequeños defectos» son indicados, globalmente, en casi todas las notas, aunque casi ninguno se atreve a enumerarlos. El crítico de Lealtad Española señalaba: «No censuramos la estructura de la obra, por más que no sea perfecta, pero sí diremos que nos repugna la acción».

Finalmente, y antes de la felicitación a autor, actores y empresa, el crítico de El Globo hace referencia a la interpretación: «El desempeño también merece plácemes. La señora Dardalla, el Sr. Vico y el Sr. Zamora fueron justamente aplaudidos; pero los honores de la fiesta pertenecen en este punto a la señorita Contreras y al Sr. Rodríguez. La primera tierna, sencilla, candorosa y siempre dentro de la situación; y el segundo, arrancando como los verdaderos artistas, aplausos hasta cuando no declamaba, sin manoteos, ni gritos, ni desplantes — perdónesenos la palabra-consiguieron anoche un verdadero triunfo». En términos parecidos se expresa El Imparcial: «La ejecución fue excelente por parte de la señorita Contreras, que en el desempeño del papel de Emilia demostró una vez más su talento artístico, arrancando en repetidas ocasiones merecidos aplausos, como también por parte del Sr. Rodríguez, y buena por parte de la Sra. Dardalla y los Sres. Vico, Zamora y Barta». Casi todas las crónicas destacan la excelente ejecución de la se- 
ñorita Contreras. Y es que, en efecto, el episodio de la seducción de la hija inocente, Emilia (interpretado por la actriz Contreras), acción secundaria en la obra, llega a despertar un interés muy superior al que se le concede a su importancia argumental. Las posibilidades de un final trágico de la obra, que le hubieran concedido un tono bien distinto, no son ignoradas por algunas reseñas inteligentes, aunque lastradas hacia la mediocre convención que valoraba más el final feliz; La Iberia afirmaba: «El drama no tiene desenlace redondo, porque para ello habría sido preciso llegar a la tragedia; pero entonces se hubiera hecho más repugnante. Se desenlaza de una manera perfectamente moral, y esto hace que deje en el ánimo más halagüeña impresión».

Suponemos que, tras la exposición de tan encomiásticas crónicas — con las obligadas excepciones, como contrapunto-, quedará al lector la razonable curiosidad de saber por qué tal obra, de un autor joven y nada conocido, llega a representarse en el primer teatro del país. Una nota de L. Bonafós — tal vez la más extensa crítica del estreno- publicada en El Correo Militar nos da cumplida noticia de tal extremo, así como de las circunstancias del autor en ese momento: «Después de algunos trabajos apreciables, debidos a expertas o respetables plumas, la empresa del Teatro Español admitió y ensayó a toda prisa por gestiones de un escritor insigne, D. Gaspar Núñez de Arce, a quien fue sometida en juicio en primera instancia, permítasenos la frase, la comedia original en tres actos y en verso, de un joven poeta, la cual lleva por título El esclavo de su culpa. El autor de la obra, D. Juan Antonio Cavestany, no cuenta todavía, según nuestras noticias, 17 años de edad; pero estudiante de derecho en la Universidad de Sevilla se ha hecho ya notable no sólo al cursar con ventaja su carrera, sino que también reveló sus disposiciones a los ocho o diez años como poeta y aún como escritor dramático, afición que parece ha alimentado siempre con el más constante y decidido estudio». Más explícita aún en el proceso previo a la representación, así como en detalles de la intervención de Núñez de Arce, Vico y Echegaray es La Correspondencia: «El Sr. Cavestany terminó en octubre su producción escénica e inmediatamente se vino a Madrid con el propósito de leerla al poeta insigne D. Gaspar Núñez de Arce, a quien sólo conocía por sus obras y sus libros. La primera lectura fue sólo del autor al poeta, e inmediatamente el Sr. Núñez de Arce fue a ver al actor Vico y le recomendó y aconsejó en bien del arte y de la empresa que se ejecutara sin dilación El esclavo de su culpa. A los cuatro o cinco días se dio lectura, a la que asistieron únicamente el Sr. Núñez de Arce, el Sr. Vico, el representante de la empresa Sr. Calle y el Sr. Echegaray, que oyó el último acto, y dio sin más razones la más cumplida enhorabuena a Cavestany. Aquel mismo día se repartieron los papeles y el público conoce el éxito». La intervención de Echegaray en favor de la representación del joven sevillano no deja de ser un dato curioso, ya que la similitud argumental de El esclavo de su culpa con En el puño de la espada (1875), el primero de los grandes éxitos de Echegaray, tras El libro talonario (1874), no deja lugar a dudas acerca de unas influencias que para algunos de los cronistas del momento fueron calificadas simple y directamente como plagio. Incluso para los críticos teatrales que quieren defenderle y ensalzarle, la falta de originalidad argumental se presenta como un problema que sólo 
puede ser superado gracias al encomio de otras dimensiones del drama. Así, el crítico de la Gaceta Comercial de Sevilla, nos dice en la nota posterior al estreno en su ciudad: «No seremos paladines de la inventiva del Sr. Cavestany, no romperemos lanzas por la originalidad de su drama; pero sí diremos a los encubiertos censores de su mérito, que si es un plagio el argumento y aun la gradación escénica de El esclavo de su culpa, no se copian la maestría en el decir, la profundidad de los conceptos, la elevación de las ideas, la pureza y sublimidad de sentimiento, la robustez y espontaneidad de la versificación, ni la expresión, juego y desarrollo de las pasiones, elementos todos con que el Sr. Cavestany ha cimentado una gloria y una reputación de literato tan elevadas, que no pueden llegar a ellas ni los envenenados alfilerazos de los Sénecas de café que le censuran ni las cobardes indicaciones de los enmascarados que le critican».

Drama de actualidad, reconocido como de pensamiento grande, elevado, moral y sublime, puso a prueba la capacidad de juicio de los críticos teatrales, algunos de los cuales, amarrados aún a la preceptiva inflexible de las tres unidades, señalaron determinados elementos distorsivos en la organización del espacio, frente al respeto a las unidades de acción y tiempo. Igualmente se destacó la fluidez y corrección versificadora, capaz de transmitir, con la impronta de la expresión clásica, problemas y aspectos sociales nuevos. Lozanía de imaginación y firmeza de juicio eran otros tantos marbetes con que se rotulaba una obra que fundamentaría y establecería un listón de éxito nuca superado por Cavestany. Obra, que, con todo, se sitúa en la misma línea de atonía y mediocridad no ya del teatro español, sino de todo el teatro europeo hasta la producción dramática de Ibsen.

El esclavo de su culpa fue, qué duda cabe, obra de extraordinario éxito. Una nota de La Época nos dice, a los tres días de su estreno: «Esta mañana a las once no había en el Teatro Español localidades para la cuarta representación de la Comedia del Sr. Cabestany (sic.) El esclavo de su culpa. La empresa ha encontrado en esta obra el premio de la lotería de Navidad». Pocos días después, desde las páginas de La Academia, se nos confirma el éxito, a la vez que, muy ponderadamente, se aventuran las claves de su aceptación por parte del público: «El estreno del drama de D. Juan Antonio Cavestany en el Teatro Español ha sido y continúa siendo un verdadero acontecimiento literario, que parece haber roto la glacial indiferencia con que las clases ilustradas miran al primero de los coliseos nacionales. El suceso no es inexplicable. No se trata de una producción cualquiera, de esas que cual fugaces meteoros pasan por la escena para dejar en ella únicamente tristes memorias, no de un fruto desabrido de escasa o fingida originalidad, ni menos uno de esos melodramas, todo artificio, donde a costa de la razón y del buen gusto se obtienen efectos ruidosos, aunque violentos y pasajeros». De esta obra se destaca — por encima de la flaqueza propia de la corta edad del autorsu categoría y empeño, espontaneidad, ingenua osadía, exquisita sensibilidad y dotes literarias y artísticas que «convierten al Sr. Cavestany en una muy legítima 
y halagüeña esperanza para nuestra decadente escena». Y un curioso juicio del cronista de La Academia: "El esclavo de su culpa es una producción que podemos clasificar de realista o naturalista, y que de uno y otro modo nada tiene de inverosímil, antes bien se modela en la vida común, donde toma su sustancia para embellecerla, no sólo en lo que toca al organismo escénico, sino en lo propio a los pensamientos y aun a la forma».

El esclavo de su culpa conoció numerosas representaciones próximas a su estreno: Málaga acogió la obra en el Cervantes, Barcelona en el Liceo, Zaragoza y Cádiz en el Teatro Principal. En todas esta capitales alcanzó un considerable éxito que podemos calificar de clamoroso en el caso del estreno sevillano. Fue el lunes 9 de enero de 1878 el día señalado para la puesta en escena en el Teatro San Fernando, en beneficio del conocido actor D. Victorino Tamayo y Baus, quien dirigió la representación y estuvo acompañado en el reparto por las actrices Villamil y Buzón y los actores Cachet y Espinosa. Al final del segundo acto fueron arrojadas al escenario cinco coronas de laurel procedentes de, entre otros, Manuel Cano y Cueto y José Gestoso y Pérez (cf. La Gaceta Comercial).

El éxito de El esclavo de su culpa, uno de los más rotundos, según hemos indicado, de la segunda mitad del XIX, puso muchas y variadas cuestiones sobre el tapete. Confrontación de criterios no sólo estéticos, sino incluso éticos. En efecto, el argumento de la obra teatral era un tanto escabroso, por más que se clausurara con un final moralizante. Y, sobre todo, parecía inadecuado para la corta edad (¡dieciséis años! de su autor). Acerca de lo primero, el Diario Mercantil de Málaga comentaba con motivo de su estreno en aquella capital: «si bien al principio aparece algún tanto inmoral e impropia por lo tanto de ser representada ante señoritas, forma un conjunto por demás interesante siendo por lo tanto digna de los nutridos y repetidos aplausos que se le tributaron». En relación con lo segundo, la adecuación entre autor y argumento, indicaba justificadoramente pero no sin cierto tono irónico de condena El Avisador Malagueño: «Para otros tiempos, quizás, eso de sorprenderse de que un niño que sólo ha vivido dos docenas de años sepa que hay mujeres seducidas en el mundo y hombres que seducen de mil modos: si el teatro mismo no nos enseñara esto todos los días y en todos los tonos, casos y formas, el mundo, que tan temprano nos recibe y tan descuidadamente nos educa, nos lo habría enseñado seguramente. Si a los siete años se fuma, a los trece se juega y a los quince se enamora, nada de particular tiene que a los veinte la ciencia de la vida amorosa esté aprendida, los secretos de erotismo se nos hayan revelado y el alma haya empezado a recorrer la senda de los desencantos, que tan derecha y rápidamente conduce a la vejez del amor».

A lo largo de las páginas anteriores hemos repasado las crónicas teatrales publicadas con motivo del éxito de Juan Antonio Cavestany El esclavo de su culpa. A partir de ellas hemos podido establecer el ámbito receptivo de dicha obra, a la vez que comprobar el anquilosamiento no sólo del teatro de finales del siglo XIX sino, también, de una crítica teatral anclada en preceptivas que en nada se 
adaptaban a las exigencias del momento. Como indicaba Alonso Cortés, en los años finales del XIX el público sólo podía elegir entre la comedia seudorromántica «de asunto histórico, de expresión lírica y desenfadada» y la comedia seudorrealista «de asunto presente, reflexiva, moral y más psicológica en situaciones y caracteres». Este segundo es el tipo de producción dramática en el que se alinea Cavestany. Con todo, le cabe el mérito de alcanzar, a tan corta edad como escribió la obra que nos ocupa, no ya el éxito, que al cabo es cuestión externa a la propia configuración del drama, sino una pieza teatral del mismo tono, corte y altura que las que entonces escribía Echegaray. Y aunque tal mérito no sea hoy reputado en mucho, no deja de ser injusta la exclusión de Cavestany de nuestras historias literarias, al par que se incluyen otros dramaturgos no ya de menor éxito, sino incluso de más insignificantes obras dramáticas. 